\title{
Legislative Norms from the Perspective of Water Resources Management in Zhejiang Province of China
}

\author{
Chencan Liu† \\ School of Public Administration, North China University of Water Resources and Electric Power, Zhengzhou 450046, \\ China \\ †Corresponding author: Chencan Liu; acan71@msn.com
}

Nat. Env. \& Poll. Tech. Website: www.neptjournal.com

Received: 02-05-2020

Revised: 14-06-2020

Accepted: 13-04-2020

\section{Key Words:}

Water resources management

Water conservation

management

Legislative norms

\begin{abstract}
As an important material resource of human being, water resource is of great significance to promote sustainable development of economy and society, and it must be managed and utilized reasonably. Water resources management in Zhejiang Province has always been at the forefront of China, but the lagging development of the local legal system has seriously hindered the construction of water ecological civilization. To meet the actual work demand of water resource management in Zhejiang Province of China, its social development and water resource management situation in 2019 was probed by using comparative analysis. Results show that water resource management and local legal system construction has a logic relationship and that their hidden dangers and shortcomings in the practice of water resources legal system in Zhejiang Province of China. Legislation standard path and countermeasures are put forward for water resources management in Zhejiang Province of China.
\end{abstract}

\section{INTRODUCTION}

At present, water security in China presents a severe situation, in which new and old problems are intertwined, especially new problems, including water resources shortage, water ecological damage, water environment pollution and so on. Water resources have become a serious shortage of products, the main factors restricting environmental quality, and the serious security problems faced by economic and social development in China. Xi Jinping, President of the People's Republic of China, pointed out that the spatial and temporal distribution of water resources was extremely uneven, and floods and droughts were frequent. To further promote the reform of water conservancy and construction of water conservancy legal system, Zhejiang Province of China carried out the project of basic research on water resource management reform and legislation according to the actual work demand of water resource management. China's current water resource management system and basin management institutions have not been effectively established which is extremely incompatible with the requirements of the situation.

Zhejiang Province of China is one of the provinces with the smallest difference in economic development. According to the sample survey of $5 \%$ opopulation change in 2019 , the province's permanent population at the end of the year was 58.5 million, with an increase of 1.1 million over the end of the previous year. According to Water Resources Bulletin of
Zhejiang Province of China issued by the water resources department in 2019, the total amount of water resources is 86.65 billion cubic meters (including underground water), which is $9.3 \%$ less than the average annual total amount of water resources, ranking the third in China after Guangdong Province and Fujian Province. Water resources protection is of great political and economic significance to the sustainable development of China's national economy. In view of the serious absence of water resources management legislation, current water resources management system and basin management institutions in Zhejiang of China have not been effectively established which is extremely incompatible with the requirements of the situation. There are problems in the legislation of water resources protection.

According to requirements of the strictest water resource management system, by using comparative analysis, this study carries out research on social development and water resource management situation in Zhejiang Province of China, and legislative study on its practice of water administration and the relevant laws and policies issued at the national level in recent years. Finally, the standard path and countermeasures are put forward.

\section{STATE OF ART}

At present, China still adopts the dual legislation mode of resource legislation and pollution prevention legislation, and 
the understanding of water resources protection is biased and comprehensive legislation is missing (Yuan et al. 2012). Moreover, laws and regulations of ecological protection of water resources are not perfect, and legislation cannot clarify the responsibilities and rights of the administrative subject, which will be a major mistake (Nie 2009). In terms of water saving management, China had established basic water saving system, but it was mainly provided in principle, and there was still a lack of special water saving laws and regulations, which was not conducive to changing the extensive use of water resources (Zhang et al. 2018). It could be seen that China's water resource management legislation was still lagging behind, and a complete set of laws and regulations system for basin water resources management had not been formed, and the expected objectives of water resources management could not be achieved (Liang 2014).

Then, it was the natural identification value of water resources legislation. Water resources management legislation should choose non-rights-based legislative model, and apply a duty-based legislative model (Smarzynska et al. 2005, Chen 2006). For the legislation of river basin water resources, the objects to be protected should be clearly specified in the legislation, and the basin water resources and ecological environment should be taken as the purpose of legislative protection (Zhou 2008).

Some scholars also carried out research on legislative countermeasures of water resources protection. Water resources legislation was not static, but dynamic, open and developing. The reform of water rights and the legal system of river basin ecological compensation should actively be promoted (Xiong et al. 2020). Comprehensive, coordinated and sustainable development as the content should be carried out, with the legislation of the scientific development con- cept, and the coordinated development of social economy and environmental protection should be achieved, to maintaining a new balance in the development (Wu 2007). A comprehensive management system and management organization should be established for the water environment and water resources basin (Du et al. 2020).

\section{WATER RESOURCE MANAGEMENT OF ZHEJIANG}

Zhejiang's GDP in 2019 was 6,235.2 billion RMB, with an increase of $6.8 \%$ over the previous year (as shown in Figure 1). Among them, the added value of the primary industry was 209.7 billion RMB, and the added value of the secondary industry is 2,656.7 billion RMB, and the added value of the tertiary industry was $3,368.8$ billion RMB, increasing by $2.0 \%, 5.9 \%$ and $7.8 \%$ respectively. The contribution rate of the tertiary industry to GDP growth was $58.9 \%$, and the added value structure of these three industries was 3.4:42.6:54.0 (as shown in Fig. 2), and the per capita GDP was 107,624 RMB (converted to 15,601 dollars at the annual average exchange rate), increasing by $5.0 \%$. In 2019, the per capita disposable income of residents in the province was 49,899 $\mathrm{RMB}$, with an increase of $8.9 \%$ over the previous year, and an increase of $5.8 \%$ after deducting the price factor. The per capita disposable income of urban and rural residents was 60,182 RMB and 29,876 RMB respectively, with an increase of $8.3 \%$ and $9.4 \%$, and an increase of $5.4 \%$ and $6.0 \%$ after deducting the price factor. The income ratio of urban and rural residents decreased from 2.04 last year to 2.01. The per capita disposable income of Zhejiang residents was 1.6 times the national average level (30,733 RMB), ranking the third in China. The per capita disposable income of urban residents is 1.4 times the national average level $(42,359$

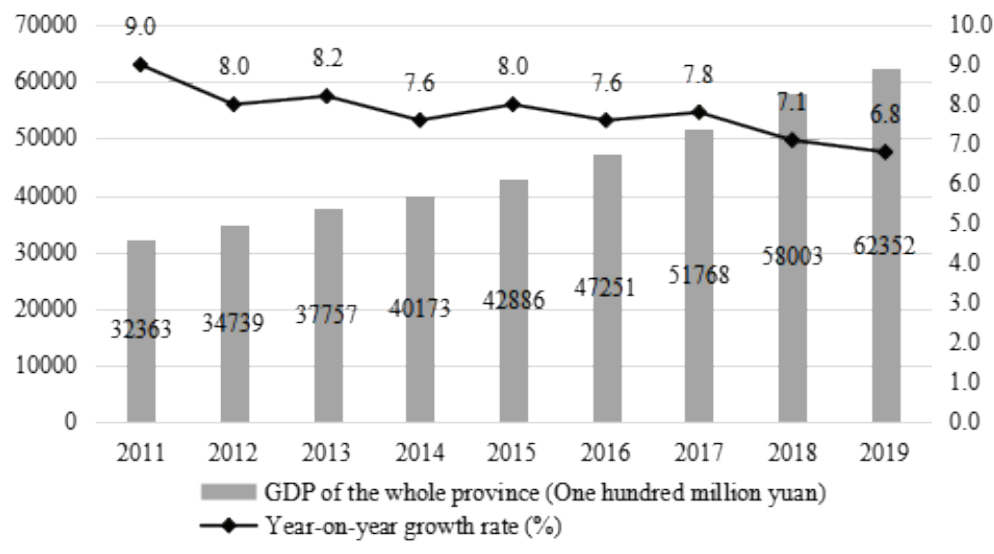

Fig. 1: GDP and growth rate of Zhejiang Province of China in 2011-2019. 


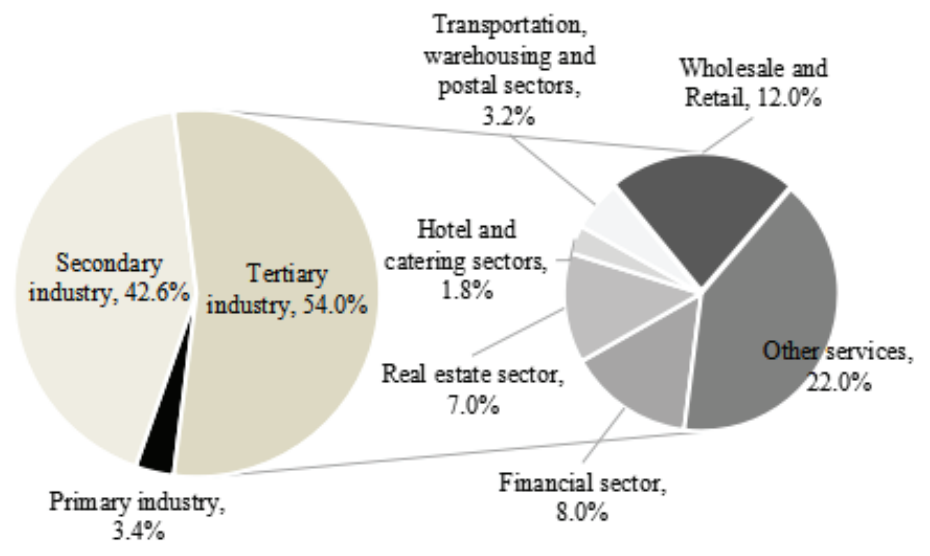

Fig. 2: Proportion of added value of various industries in regional GDP of Zhejiang Province of China in 2019.

$\mathrm{RMB}$ ), ranking the third in China. The per capita disposable income of rural residents is 1.9 times the national average level (16,021 RMB), ranking the second in the country. On the whole, the economy in Zhejiang is running steadily and making progress instability, and the trend of major economic indicators is better than that of the whole country.

The average precipitation of the whole province is $1,640.3 \mathrm{~mm}$, which is $2.3 \%$ more than the average annual precipitation. The total annual water consumption of the whole province is 17.4 billion cubic meters. Domestic water consumption of residents is 2.856 billion cubic meters, accounting for $16.4 \%$. Water consumption of ecological environment is 550 million cubic meters, accounting for $3.2 \%$ (as shown in Fig. 3). There are 194 large and medium-sized reservoirs in the province, with a total storage capacity of 24.3 billion cubic meters at the end of the year, including 34 large reservoirs, with a total storage capacity of 21.9 billion cubic meters. It has an increase of 1.8 billion cubic meters compared with the end of the previous year. In addition, there are 160 medium-sized reservoirs, with a total storage capacity of 2.4 billion cubic meters at the end of the year, an increase of 299 million cubic meters compared with the end of the previous year. There are 1,112 water function areas in the whole province, with 16,923 kilometres of river length. There are 717 key water function areas assessed by the province during the 13th five-year plan, with a total river length of 12,114 kilometres. The annual compliance rate is 89.1\% (as shown in Figure 4).

In the aspect of water resource management system construction, Zhejiang Province of China has made remarkable achievements depending on the long-term economic foundation. Water Resources Management Regulations of Zhejiang Province was the first local regulation regulating water resources management in China since Water Law of the People's Republic of China. The purpose was to reasonably develop, utilize, save and protect water resources, and to provide a legal basis for strengthening the unified management of water resources quality and quantity. It tried to explore the

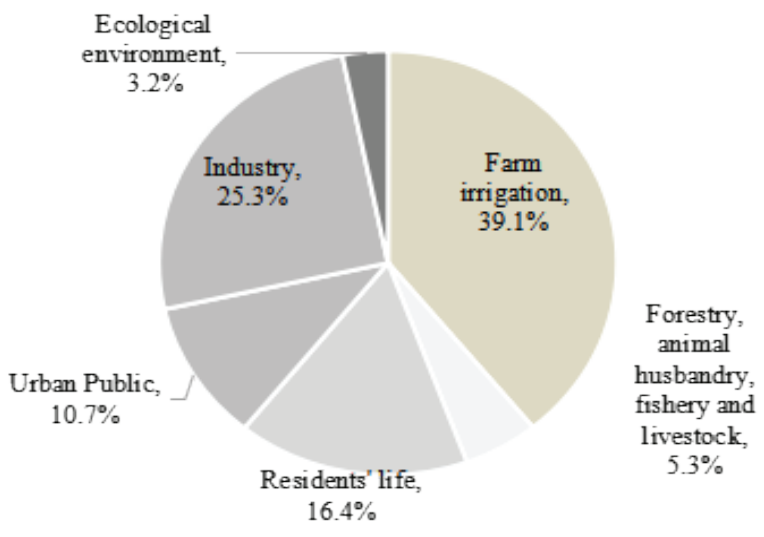

Fig. 3: Schematic diagram of water structure proportion of the whole province in China. 


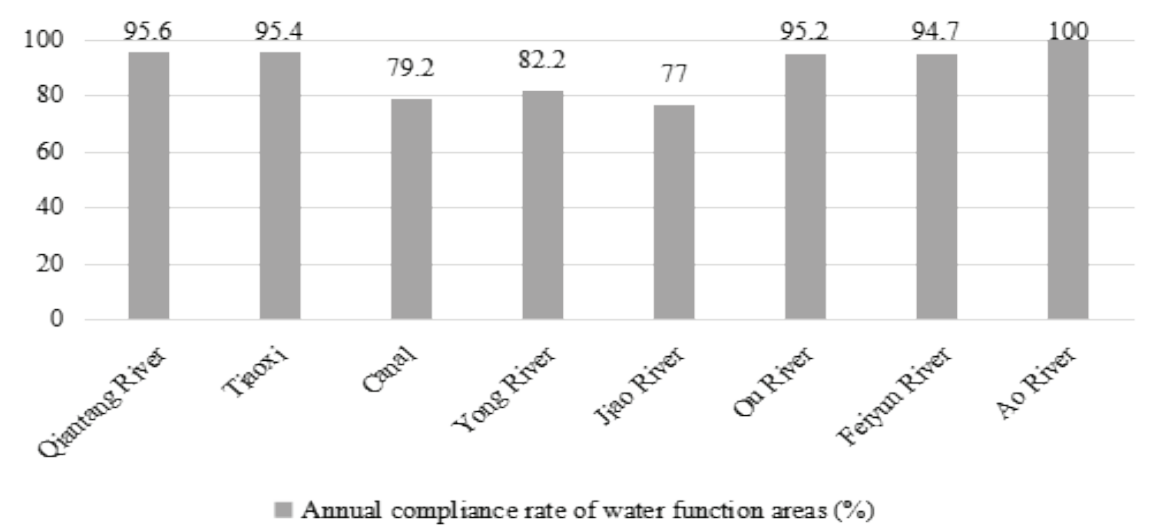

Fig. 4: Water quality compliance rates of eight water system water function areas.

initial water right distribution scheme. Zhejiang Province was one of the earliest provinces to carry out the administrative legislation of water conservation management. Water Conservation Measures of Zhejiang Province was implemented. In addition, Zhejiang Province had organized and compiled a series of water resource management plans, including Master plan for water resources protection, development and utilization, water-saving society construction plan, water-saving irrigation plan, and water resources protection. It also issued a series of normative documents, including opinions on promoting the construction of water ecological civilization, the implementation plan for accelerating the construction of water-saving society in Zhejiang Province of China. For further improving water-saving management system and water resource protection system of Zhejiang Province of China, it provided a strong legal basis and system guarantee for the provincial water administration, and also provided a "Zhejiang Model" of China for the national water resource management.

Although Zhejiang Province is rich in total water resources in China, the per capita water volume is only about $1800 \mathrm{~m}^{3}$, about 8 percentage points lower than the national per capita level, which is less than $1 / 4$ of the world per capita level. In recent years, with the rapid growth of urban and industrial water consumption, the contradiction between water supply and demand in Zhejiang Province is very prominent, especially the general shortage of water resources in most islands in the province, and the serious shortage of production and domestic water supply. In addition, deterioration of water environment, degradation of water ecology and overdraft of groundwater lead to the water crisis are imminent. At present, there are new problems in water resource management of Zhejiang Province of China. Water administration is decentralized, involving multiple management departments, and it is difficult to adapt to the complex relationship of the water system. What's worse, economic leverage of water resource management is limited, which may mains that the water price system is unreasonable, and that the market-oriented policy is not mature. It is urgent to promote water price reform and to improve the water price system. Supporting system of water resource management is insufficient, especially the auxiliary information system of water resource management, and the illegal disposal is lack of force. Official publicity and education of water conservation and water resource protection are not enough, and the public awareness of water conservation and participation is not generally formed. It can be seen that the current water law and regulation system in Zhejiang Province of China has seriously lagged behind economic development and that local legislation should be adopted to strengthen the administrative management of water resources.

\section{LEGISLATIVE AND FEASIBILITY ANALYSIS}

Because of the actual work demand of water resources management in Zhejiang Province of China, this study puts forward the legislative amendment proposal of organic integration of Water Resources Management Regulations of Zhejiang Province and Water Conservation Measures of Zhejiang Province. Based on the previous legislative research, Water Resources Management Regulations of Zhejiang Province and Water Conservation Measures of Zhejiang Province will be merged, and Regulations on Water Conservation and Water Resource Management of Zhejiang Province of China with legality, rationality, coordination, operability and standardization will be promulgated and implemented through legislative channels (Bravo-Macias et al. 2019). Raising "water conservation" to the same legal level as "water resource management" can effectively regulate current water administration behaviour. It also can improve public awareness of water conservation and environmental 
protection, which has the significance of the rule of law and practical feasibility of the times.

Firstly, it should meet the needs of the practice of the new concept of water control. Water-saving has been mentioned at an unprecedented height, and it can be made a conscious action for individuals and social organizations. It is required to vigorously publicize the behaviour of water-saving and water cleaning. It is necessary for Zhejiang Province of China to comprehensively summarize the experience, to find out weak links of water-saving work, and to put forward targeted system and mechanism guarantee. The effective integration of Water Resources Management Regulations of Zhejiang Province and Water Conservation Measures of Zhejiang Province will also enhance the legal status of water-saving management. The new idea of water control in the new era should be put into practice. The management system should be further improved, and the management ability should be improved to better realize the purpose of water resource conservation and protection in Zhejiang Province of China.

Secondly, it should adapt to the needs of ecological civilization system reform. With the national attention to the construction of water ecological civilization year by year, a series of important water administration measures have been announced in succession. Methods include implementing the strictest water resource management system, promoting the implementation of water pollution prevention and controlling action plan, strongly promoting the river lake system and "five water co-governance", etc., which have a profound impact on water resource management reform and legal system construction in Zhejiang Province. It has made beneficial explorations and accumulated practical experience in aspects of the strictest assessment of water resource management system, construction of water-saving society, reform of water licensing, demonstration of planned water resources, compensation of basin ecological protection, and reform of water right system. In the future, promulgation and implementation of Regulations on Water Conservation and Water Resources Management of Zhejiang Province will consolidate practical experience and reform achievements by means of the rule of law and will continue to guide and promote reform and development of the water ecological civilization system in Zhejiang Province.

Thirdly, it should ensure sustainable development of economy and society. Water resources are a basic guarantee for sustainable development of economy and society and construction of ecological civilization. Rapid economic and social development has brought deep structural changes in water supply and demand. As an economically developed region in China, Zhejiang Province is facing with severe challenges in the new era, which needs to further promote reform of water resources supply, to adhere to the water resources management principle of "Water determines the city, the land, the people and the production", to take actions by measuring the number of water resources, and measures according to the situation of water resources, and to strengthen rigid restriction of water resources. Both Water Resources Management Regulations of Zhejiang Province and Water Conservation Measures of Zhejiang Province are not in line with current water resources development situation in Zhejiang Province of China, so it is urgent to comprehensively revise and integrate them, and to provide effective legal support for water resources management reform through the way of national coercive force.

Finally, it should meet the needs of water conservation and management according to law. China has promulgated a series of basic water laws, including Water Law, Law on Prevention and Control of Water Pollution, Law on Soil and Water Conservation and Flood Control Law. However, there are some problems in judicial practice, such as the weakness of water laws and regulations, and the lack of initiative and legitimacy of local water administrative departments to manage water according to law, which may lead to the phenomenon of weak operation of the local legal system and lax law enforcement, and the result of the reduced force of water laws. Through the implementation of the new Regulations on Water Conservation and Water Resource Management of Zhejiang Province of China, a series of basic systems for water conservation and water resource management will be established from perspective of the rule of law to ensure legalization and standardization, to clarify legal obligations and responsibilities of water conservation and protection of water resources in the whole society, and to form a good social water resource environment for the whole people to manage and protect water according to law.

\section{PATH OF LOCAL LAWS AND REGULATIONS OF WATER RESOURCES MANAGEMENT}

\section{The Path of Legislative Norms Based on Water Resources Management Regulations of Zhejiang Province Perspective}

As the first local law of water resource management in China, Water Resources Management Regulations of Zhejiang Province has played an important role in strengthening water resource utilization planning, reducing water pollution, improving water resource utilization efficiency and promoting social sustainable development since its implementation in 2002 (Copeland et al. 2003). Attention should be paid to the implementation of local system guarantee in the strictest water resource management work in the country, which can 
be further modified and improved in the following aspects.

Firstly, the rules of the water efficiency control system need to be detailed. The efficiency of water use is not high and the shortage of water resources has become an important restricting factor for the sustainable development of economy and society. The provisions set up the basic framework of water use efficiency control in the Water Resources Management Regulations of Zhejiang Province. From the perspective of relationship with Water Law, it stipulates obligations of the state and the government, obligations of units and individuals to save water, improvement of agricultural water use efficiency, and improvement of industrial water use efficiency, water-saving facilities and water-saving instruments. There is no problem with their legality. However, compared with the lower law, the provisions of Water Resources Management Regulations of Zhejiang Province are still rough. Regulations on Water Conservation and Water Resource Management of Zhejiang Province should be incorporated to some extent.

Secondly, the content of water function zone pollution control system needs to be expanded. The core content of the system is to strengthen supervision and monitoring and to carry out protection and repair. The provisions of Water Resources Management Regulations of Zhejiang Province on the total emission are relatively simple, only stipulating that the government puts forward opinions on the total emission to competent environmental authorities and that provisions of the upper law should be appropriately absorbed. It is necessary to refer to the relevant provisions of "restoration of water ecological system" in Environmental protection law, and at the same time set up the main responsibility for violating the protection of water ecological system.

Thirdly, water resource management assessment system needs to be established. Water resource management responsibility and assessment system is the fundamental guarantee to implement the strictest water resource management system, which is easy to be ignored in practice. The overall system arrangement can be made by referring to provisions of opinions on implementing the strictest water resource management system of the State Council, and its principle, subject, content, method, period, plan and report shall be specified.

\section{The Path of Legislative Norms Based on Water Conservation Measures of Zhejiang Province Perspective}

Water Conservation Measures of Zhejiang Province is a special government regulation of Zhejiang Province in China, which can more comprehensively and systematically regulate series of water conservation management systems or penalties, further clarify and refine the important systems in Water Resources Management Regulations of Zhejiang Province, and can make up for the shortcomings of Water Resources Management Regulations of Zhejiang Province in-depth and breadth. To sum up, the revision of Water Conservation Measures of Zhejiang Province can be divided into two parts. Firstly, it revises the water conservation clause in Water Resources Management Regulations of Zhejiang Province. Then, it merges with Water Resources Management Regulations of Zhejiang Province to form Regulations on Water Conservation and Water Resource Management of Zhejiang Province (Draft) of China and improves the refinement and overall planning of the system. The specific revision suggestions are as follows.

Firstly, it's what needs to be improved. For the problems of unclear and repeated responsibilities in Water Conservation Measures of Zhejiang Province, it is necessary to clarify the responsibilities of water-saving management, and effectively to connect the water-saving management work of each link in combination with the "three definite plans" of the water-related management department. The provincial water administrative department is responsible for formulating water-saving policies, preparing water-saving plans, standardizing water-saving standards, guiding the construction and management of water-saving irrigation projects, and assessing with relevant departments to promote the construction of a water-saving society in the province (Kolkis 2019). It is necessary to improve the water-saving planning system and clarify corresponding formulation, implementation and revision departments. Water Conservation Measures of Zhejiang Province shall specify the system to be implemented for water fee collection, and shall implement the system of over plan and over quota progressive price increase. It is stipulated that water users shall use water according to the approved plan index or water quota. If water consumption exceeds the plan and over quota, water fee exceeding the plan shall be increased according to the method of the progressive price increase. The provisions of Water Conservation Measures of Zhejiang Province that lack water-saving reward and punishment is too light should be modified. The people's government at or above the county level shall establish a special fund for the reward of water-saving technology research, development, promotion of water-saving facilities construction and water-saving management. For violations of water-saving regulations, bad information shall be included in the credit file following the provisions of Zhejiang credit rules.

Secondly, it's what needs to be added. "Contract water-saving" provisions shall be added to encourage the development of water-saving service institutions, and to support water-saving service institutions to carry out con- 
tract water-saving, water-saving consultation, water balance test and other services. It shall recover investment and obtain reasonable profits in the way of water conservation benefit-sharing, and shall carry out contract water-saving management in public institutions, high water consumption industry, high water consumption service industry, efficient water-saving irrigation and other fields. The quality supervision department shall conduct supervision, spot check, special inspection and verification management for the products listed in the list of water efficiency identification products according to law. Products and equipment that have obtained water-saving product certification in accordance with relevant regulations should be listed in the list of government procurement with priority. In addition, it shall implement the "water efficiency leader" system, establish a water efficiency leader system, develop indicators for water efficiency leaders, and shall carry out leading actions for water efficiency leaders in the fields of industry, agriculture, public institutions and domestic water use.

Thirdly, in view of the need for a large number of technical personnel and complete technical support, the administrative cost of the water-saving audit is too high, which is not suitable for water resources and environment of Zhejiang Province of China, and it should be abolished. Due to the lack of sufficient technical force, it is difficult for rural water management institutions to undertake the responsibility of managing and maintaining agricultural irrigation water-saving facilities, which is not suitable to name the water management organization established by the rural collective economic organization. Since water quotas are usually set by industry authorities in practice, the intervention of local governments should be deleted due to the lack of operational procedures.

\section{CONCLUSIONS}

Water Resources Management Regulations of Zhejiang Province belongs to local laws and regulations in the nature of law. Local laws and regulations occupy an important legal position in the socialist legal system of our country. In order to build a legal society, attention should not only be paid to the formulation of local laws and regulations but also should be paid to actual operation state, together with results and existing problems after the formulation of laws and regulations. Although Water Resources Management Regulations of Zhejiang Province had been revised three times in 2009, 2011 and 2017, so far, it was difficult to meet new ideas and requirements for water conservancy work and was also hard to cope with new problems and situations in water administration of Zhejiang Province of China. Its legal norms and legal objectives are not compatible with the current water-saving management work. Meanwhile, Water Conservation Measures of Zhejiang Province has not taken the protection and improvement of ecological environment as the basic purpose of the legislation, seriously lagging behind the water administration work of Zhejiang Province of China, with poor timeliness. The revised Water Law in 2016 marked a new stage in the construction of the rule of law for water control and protection according to law. Zhejiang Province is one of the first provinces to make local legislation on water resources management, and evaluation of water resources has been at the forefront of China.

\section{ACKNOWLEDGEMENT}

This work is supported by the Philosophy and Social Science Planning Project of Henan Province (No. 2018CZZ011), the Philosophy and Social Science Innovation Team of Henan University (No. 2020-CXTD-09), and the General Project of Humanities and Social Science of Henan Education Department (No. 2019-ZDH-683).

\section{REFERENCES}

Bravo-Macias, C., Sarmentero-Bon, I., Rodriguez-Sanchez, Y. and Gomez-Figueroa, O. 2019. Evaluation of organizational competencies through performance indicators. Dyna, 94(5): 490.

Chen, X.J. 2006. A new exploration of watershed legislation. Journal of Zhengzhou University (Philosophy and Social Science Edition), 47(5): 61-65.

Copeland, B. and Taylor, S. 2003. Trade and the Environment: Theory and Evidence. Princeton University Press, Princeton.

Du, Y. C. and Wang, R. X. 2020. Impact of corporate governance ability on capital gains in mixed ownership enterprises. Transformations in Business \& Economics, 19(2): 92-113.

Kolkis, S. 2019. Benchmarking the sustainability of urban energy, water and environment systems and envisioning a cross-sectoral scenario for the future. Renewable and Sustainable Energy Reviews, 103: 529-545.

Liang, J.Y. 2014. A Study on the legislation of water resources management in river basins in China. Environmental Science and Management, 40(2): 178-181.

Nie, A.P. 2009. Discussion on legislation of water resources ecological protection in China. Jiangxi Social Sciences, 9(11): 141-144.

Smarzynska, B.K. and Wei, S.J. 2005. Pollution havens and foreign direct investment: Dirty secret or popular myth. Economic Analysis \& Policy, 3(2): 8-38.

Wu, Y. P. 2007. Research on integrated management system of water environment and water resources basin. Hebei Law, 28(7): 119-123.

Xiong, Z., Wang, P.J. and Zhao, Y. 2020. Re-innovation from failure, institutional environmental differences, and firm performance: Evidence from China. Amfiteatru Economic, 22(53): 197-219.

Yuan, J.W. and Tu, J.F. 2012. Legislative status and improvement of water resources protection in China. Journal of Hubei University of Economics (Humanities and Social Sciences), 9(11): 74-75.

Zhang, R.M., Wang, Y.J. and Chen, X. 2018. Current situation of water resources management legislation and new requirements of supply side reform. Water Economics, 38(1): 27-31. 